\title{
Urnas de tradición indígena en Corduba - Colonia Patricia. Una PROPUESTA ACTUALIZADA PARA EL ÁMBITO FUNERARIO
}

\author{
Indigenous tradition urns in Corduba - Colonia Patricia. An updated proposal for understanding the funerary \\ contexts
}

\section{ANA B. RUIZ OSUNA ${ }^{1}$, MANUEL RUBIO VALVERDE ${ }^{2}$}

(1) Universidad de Córdoba.aa2ruosa@uco.es

(2) manuelrubiovalverde@gmail.com

\section{Resumen:}

Las urnas de tradición indígena configuran uno de los conjuntos cerámicos más interesantes de la península Ibérica, tanto por sus orígenes como por su continuidad en época romana. Uno de los usos más significativos fue el de contenedor de restos óseos procedentes de las cremaciones, aunque también acogieron inhumaciones infantiles. Los recientes hallazgos que se han producido en diversas excavaciones en la ciudad de Córdoba nos permiten retomar cuestiones ya planteadas sobre tipología, usos, rituales y etnicidad en las necrópolis de Corduba - Colonia Patricia.

Palabras clave: urnas de tradición indígena, necrópolis romanas, tipologías, etnicidad.

\section{Abstract:}

The indigenous tradition urns constitute one of the most interesting ceramic ensembles on the Iberian Peninsula, both for their origins and for their continuity in Roman times. One of the most significant uses was as a container for bone remains from cremations, although they also housed child inhumations. Recent findings in various excavations in the city of Cordoba allow us to return to matters already formulated concerning typology, uses, rituals and ethnicity in the necropolis of Corduba-Colonia Patricia.

Key words: Indigenous tradition urns, roman necropolis, typologies, ethnicity. 
Aun cuando su presencia se constata en prácticamente toda la península Ibérica, la falta de excavaciones sistemáticas, la ausencia de publicaciones específicas y la variedad de tipos existentes en cada región, hacen difícil establecer su origen y evolución. Los primeros estudios sobre esta tipología, que forma parte de los grandes repertorios de cerámica común o cerámica pintada de época romana, nos remiten a obras como las de M. Vegas (1973) y J. M. Abascal (1986), en las que se establecen series globales. Desde la década de los 70 del s. XX son numerosas las tipologías sobre cerámica ibérica que se han publicado (vid. Pereira 1988 y 1989; Escacena 1987; Ruiz y Molinos 1993; Conde 1998; Olmos y Rouillard 2004); sin embargo, en el caso concreto de las que sirvieron como ollae ossuariae nos encontramos con marcos cronológicos tan amplios que resultan del todo inútiles como herramientas de datación.

Este es el caso de las necrópolis ibéricas del SE andaluz, comprendidas grosso modo entre los ss. V y III a.C., donde la mayoría de los ejemplos carecen del contexto original de hallazgo (Pereira 1988). Por lo general, se trata de contenedores que muestran formas constantes, que nos remiten a tipos mediterráneos tradicionales y vasos autóctonos con precedentes en etapas anteriores. En cuanto a la decoración resultan también bastante uniformes, con un predominio de bandas horizontales estrechas y polícromas, con alternancia de semicírculos concéntricos, cuartos de círculo y líneas de agua en un primer momento, y simples líneas monocromas de distintos grosores en épocas posteriores (Escacena 1987).
Por lo que se refiere a las necrópolis republicanas volvemos a encontrarnos con una situación esquiva, siendo pocos los espacios funerarios conocidos o reconocidos como tales. La mayoría son necrópolis con precedentes indígenas que continúan en uso hasta los ss. I-II d.C., a saber: Castellones de Ceal (ss. IV-II a.C.) (Chapa et al. 1998); La Guardia (ss. IV a.C. - I d.C.) (Blanco 1959; 1960); Castulo (ss. V a.C. - II d.C.) (García Gelabert y Blázquez 1992); Giribaile (ss. IV - I a.C.) (Gutiérrez e Izquierdo 2001); Toya (ss. V-III a.C.) (Cabré 1925; Mergelina 1944); Galera (ss. V a.C. - I d.C.) (Cuadrado 1981; Pereira et al. 2004); Osuna (ss. VII - I a.C.) (Campos 1989; Escacena y Belén 1994; Chaves 2002); Cerro de las Balas (ss. III-I a.C.) (Núñez y Muñoz 1990); y Cerro de la Cruz (ss. IV-II a.C.) (Vaquerizo 1994; 1999); entre otras. Más recientemente se han llevado estudios sobre Baelo Claudia (Prados 2016) y la zona extremeña (Bustamante 2016).

En el caso concreto de Córdoba, la ausencia de evidencias funerarias anteriores a la llegada de los contingentes romanos sigue siendo una constante. Tan sólo un hallazgo procedente del área occidental de la Colina de los Quemados (fig. 1), lugar originario del poblado prerromano Corduba, podría plantear la existencia de un espacio funerario en este sector de la ciudad (Murillo y Jiménez 2002: 186 ss.). El problema es que el conjunto, compuesto por una urna de tradición indígena con platotapadera, un fragmento de cuchillo de hierro y una pieza de cerámica campaniense fechada entre 210-190 a.C., fue recuperado del mercado clandestino. En realidad, los

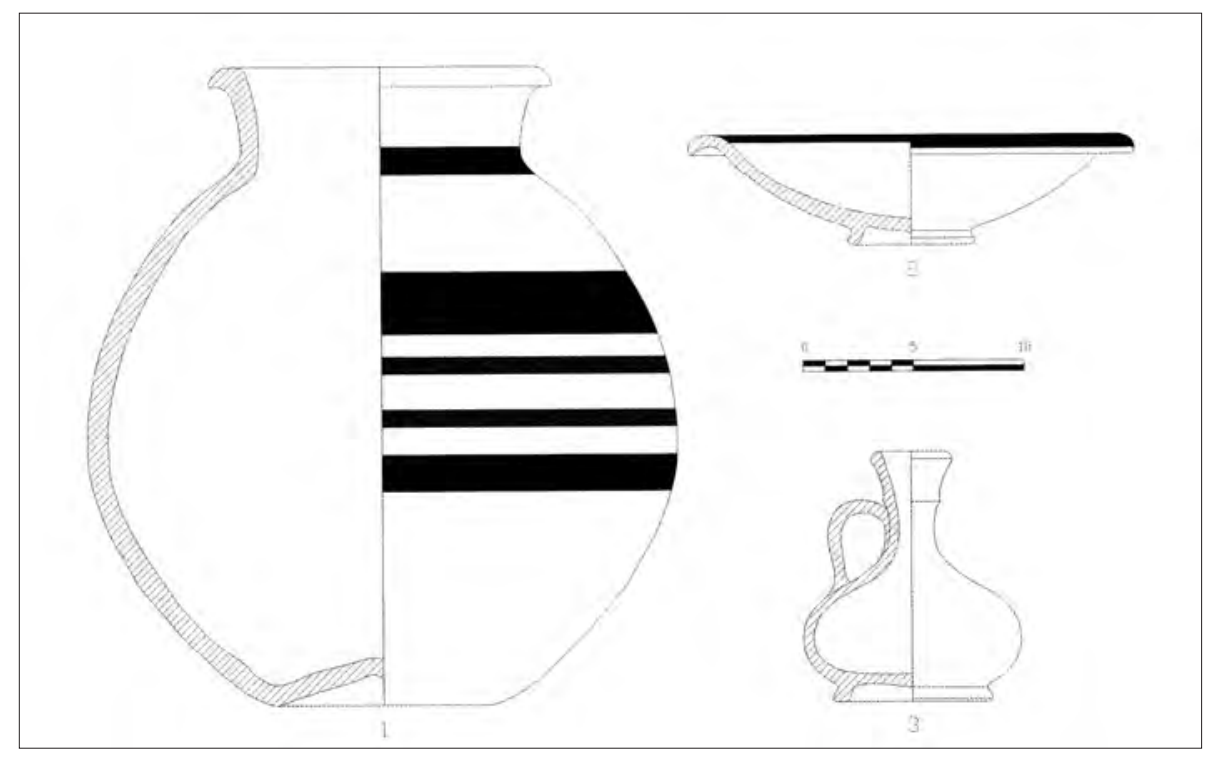

Fig. 1: Urna de tradición indígena con ajuar procedente de un contexto desconocido de Córdoba (Murillo y Jiménez 2002: 186 ss.). 
primeros hallazgos seguros de índole funeraria en Córdoba nos remiten a fechas tardorrepublicanas, tal como se desprende de algunos epitafios en bloques de piedra (Ruiz Osuna 2007a: 125), varios elementos arquitectónicos (Márquez 1998: 106 ss.; 2002: 226; Vaquerizo 2001a: 145), y una serie de recintos funerarios ubicados en las proximidades de las principales puertas de la urbe y vías de comunicación (Vaquerizo 2001b: 169-205; 2020). Todas estas manifestaciones responden a modelos de influencia itálica (edícolas, altares, recintos), traídos, seguramente, por los propios colonos asentados ya en la ciudad, los cuales permanecerían fieles a sus tradiciones y costumbres, poniendo las bases de la llamada monumentalización funeraria (vid. Ruiz Osuna 2007a).

Ante este panorama, resulta admirable la labor de investigación emprendida por B. García Matamala (2002; 2002-2003; 2006) sobre las urnas de tradición indígena en la capital cordobesa. Sus trabajos recogían los ejemplares conocidos hasta ese momento, un total de 19 procedentes tanto de excavaciones antiguas como de otras más recientes. Este repertorio cerámico permitió establecer cinco tipologías, teniendo en cuenta la morfología y decoración, con paralelos en otras necrópolis hispanas del momento (Castulo, Pajar de Artillo, Ampurias, Carmona, Baria, Peñarrubia y Villa de los Castillones), y con precedentes en necrópolis indígenas cercanas (Almedinilla, Alhonoz, Camorra de las Cabezuelas). Se trata de ejemplares encuadrados entre época tardorrepublicana y la primera mitad del s I d.C., que acogían principalmente restos óseos cremados (tres de ellos infantiles); si bien, se documentaron siete casos en los que las urnas de tradición indígena sirvieron como contenedores de inhumaciones infantiles (García Matamala 2002-2003: 268; 2006: 100 ss.).

\section{NUEVOS HALLAZGOS EN NECRÓPOLIS COR- DUBENSES}

Desde los estudios de B. García Matamala (vid. supra) son numerosas las excavaciones que se han ido desarrollando en entornos funerarios de la antigua Corduba - Colonia Patricia, las cuales han venido a completar la información disponible hasta la fecha (fig. 2). Entre los trabajos arqueológicos a los que vamos a hacer referencia, los cuales nos remiten en la mayoría de los casos a tumbas aisladas, destacan especialmente los conjuntos de la calle Beatriz Enríquez y avenida Llanos del Pretorio, que han ofrecido 19 y 46 ejemplares, respectivamente, lo que sumado a la detección de varias fases de uso dentro de las propias necrópolis, su disposición en el interior de recintos funerarios lotificados y la existencia de ajuares funerarios contextualizados, nos permitirá avanzar en las propuestas tipológicas y cronológicas hasta ahora conocidas, así como en las usanzas de las urnas de tradición indígena en la capital de la Bética.

\section{AVENIDA DEL CORREGIDOR (fig. 2, 1)}

Las obras de un colector en la Avenida del Corregidor permitieron poner al descubierto una nueva zona de necrópolis en el entorno del conocido como "Camino de las Abejorreras" (Vargas y Gutiérrez 2004: 309-328; Ruiz Osuna 2010b: 380-405). Aunque no mostraba rasgos de monumentalización, este espacio funerario volvía a hacer gala de una parcelación previa del terreno a través de cipos y recintos, así como de un cuidado permanente gracias a la reparación de suelos tras cada crecida del río Baetis (hoy Guadalquivir). Su inicio se sitúa en época protoaugustea, en un momento previo a la organización estructural del sepulcretum, donde encontramos una tumba de cremación interpretada como bustum (Tumba 15), en cuyo interior se depositó una urna de tradición indígena junto a un ungüentario de vidrio (Isings 6) (Vargas y Gutiérrez 2004: 232 ss.). A la fase siguiente, también de época augustea, pertenece la Tumba 67 identificada con una estructura de ladrillos de 79 × $30 \mathrm{~cm}$, dividida en dos compartimentos: uno para llevar a cabo la cremación y otro para acoger la urna cineraria de tradición indígena identificada con el Tipo V de B. García Matamala.

\section{CALLE ANTONIO MAURA No 10 (fig. 2, 2)}

Situada junto a la antigua via Corduba-Hispalis, en el suburbium occidental, la excavación documentó varias fases de uso funerario de las que destacaremos la adscrita a época altoimperial (Martín Blanco 2007). Nos referimos a varias tumbas de cremación, algunas de ellas identificadas solo a través de las manchas de combustión interpretadas como busta. Además de estos conjuntos de cenizas, fueron localizadas dos tumbas de carácter secundario: una de ellas respondía al Tipo V de B. García Matamala, en cuyo interior se localizaron restos óseos cremados y fragmentos de un ungüentario de vidrio; todo ello cubierto con los restos de otra urna. El hallazgo de parte de una estructura realizada a base de 

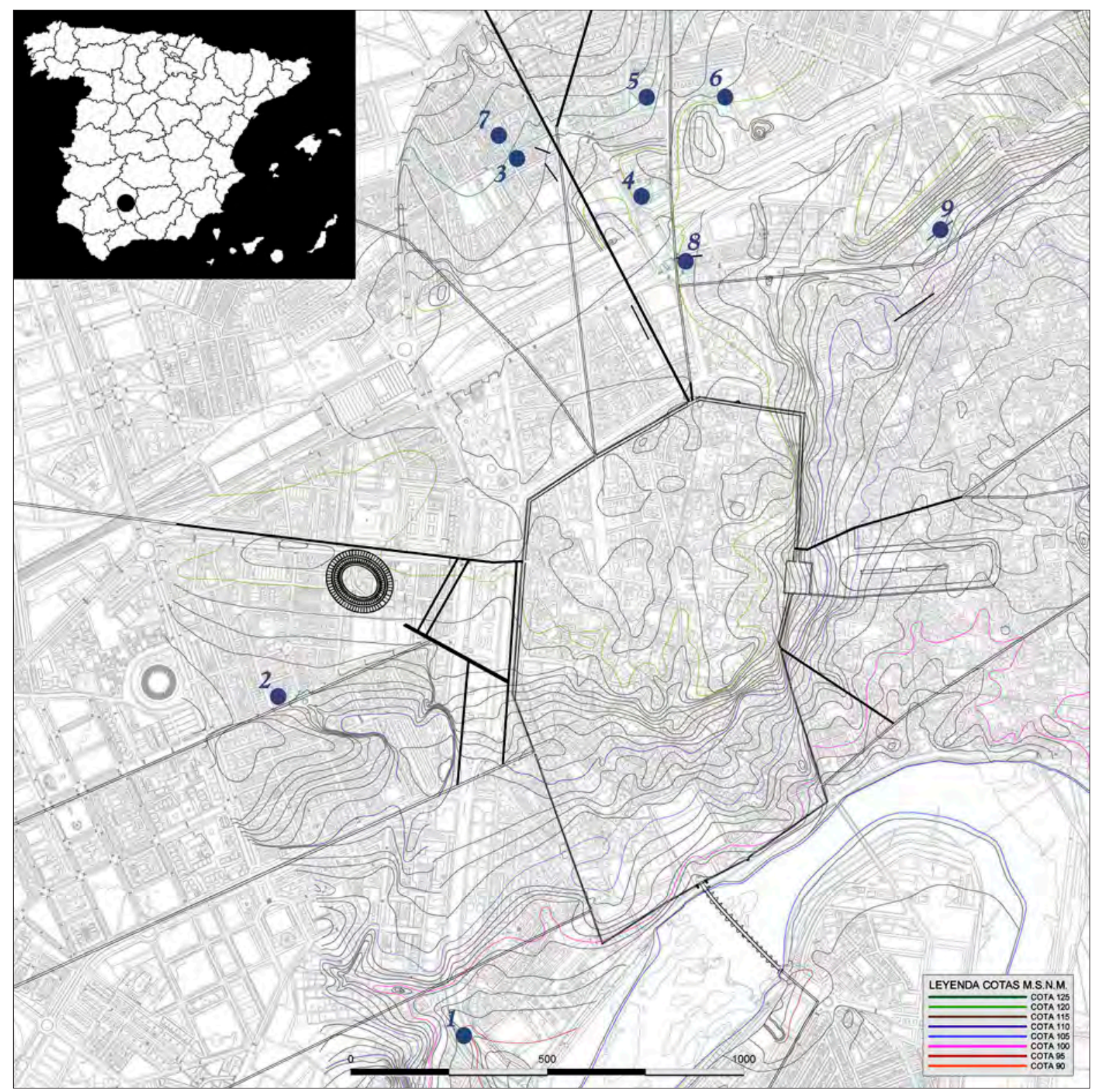

Fig. 2: Plano de dispersión de los nuevos hallazgos funerarios con presencia de urnas de tradición indígena en Córdoba. Elaboración propia.

cantos rodados podría hacer pensar en la existencia de algún acotado funerario o muro de delimitación de este sector de necrópolis.

\section{CALLE BEATRIZ ENRÍQUEZ (fig. 2, 3)}

El solar arrojó casi 70 enterramientos de época altoimperial, fechados entre época tiberiana y vespasiana, siendo la principal problemática que nos encontramos a la hora de abordar su estudio tipológico el degradado estado de conservación en el que fue encontrada, con piezas cerámicas muy fragmentadas, así como la parca descripción y ausencia de material gráfico en el informe de excavación (López Palomo 2004). Aun así, hemos podido diferenciar con claridad dos urnas del Tipo III de B. García Matamala, y otras dos algo más dudosas, especialmente la clasificada como UE 20 , identificada con una cremación infantil por el tamaño de la urna, que se 
hizo acompañar de una lucerna de venera y un ungüentario. Algunas de las ollae presentaban decoración de líneas vinosas y tan sólo el bustum donde apareció la urna UE 126, cubierta con una tegula, presentaba restos de ajuar, concretamente, una lucerna de volutas con representación de un perro atado a un árbol. Resulta curioso que el Tipo $\mathrm{V}$ de B. García Matamala, uno de los más abundantes en las necrópolis cordubenses, apenas tenga presencia en este yacimiento, suponiendo su existencia en un único ejemplar que se describe como urna cineraria con asas verticales (UE 161). De gran interés son las urnas cerámicas que muestran ciertas variantes con respecto a los tipos establecidos y que vendrían a ampliar el conjunto conocido hasta la fecha en la ciudad. Así pues, dentro del Tipo II cabe establecer la urna identificada con la UE 194, mientras que reconocemos un nuevo tipo con asa lateral en la UE 51, ambas cubiertas con un platito de tradición indígena. Igualmente, podemos hablar de un Subtipo IV sin asas, como así demuestran la UE 42, perteneciente a una cremación infantil introducida, a su vez, en un ánfora; y la UE 90, que contaba como único ajuar con un vasito de paredes finas.

SEDE DE EMACSA (AVDA. DEL PRETORIO, 4) (fig. $2,4)$

Las investigaciones arqueológicas han puesto de manifiesto el uso funerario e industrial que tuvo el suburbium septentrional, tal como demuestra en este caso el hallazgo de dos hornos cerámicos y una estructura funeraria interpretada como un bustum-ustrinum (Cánovas et al. 2006). Esta última presentaba planta rectangular $(2,25 \times 1,25 \mathrm{~m}$, aproximadamente), estando realizada en opus quadratum, con una fase de recrecimiento que pone en evidencia un uso múltiple y dilatado en el tiempo, tal como confirma la presencia de cinco cremaciones en su interior. La más antigua contaba con una urna de cerámica común y un lebrillo de tradición ibérica decorado con círculos concéntricos. Esta decoración tan arcaizante no es propia de la primera mitad del s. I d.C. Se trataría, según Cánovas et al. (2006: 284), de un fenómeno aislado, que podría hacer alusión al depósito de piezas ancestrales o de cierto valor sentimental, sin que podamos descartar la idea de que se fabricara en un momento coetáneo al enterramiento, datado en época de Claudio ${ }^{1}$. La segunda cremación, de fechas neronianas, presentaba una urna de cerámica con una ranura en el borde para encajar la tapadera. La pieza resulta bastante estilizada, con pie muy estrecho, que va dando paso a una forma caliciforme, sin ningún tipo de decoración. El ajuar repite modelos vistos con anterioridad, basado en la presencia de nueve piezas de cerámica Peñaflor (tres platos, tres tazas y tres tacitas), a las que se le suman una orcita de cerámica común, una lucerna de venera y otra de disco y una moneda de bronce (Cánovas et al. 2006: 286). La siguiente cremación contaba con una urna de borde exvasado y acanalado al exterior, muy habitual en el repertorio de cerámica común de la época. Por su parte, la tapadera sigue la tipología formal de las de tradición indígena, pese a que no presenta la característica decoración en color ocre (Cánovas et al. 2006: 288). El ajuar estaba compuesto por un plato, una jarra, una piedra pómez de forma troncopiramidal y una lucerna con representación de antorcha y guirnalda, lo que permite situarlo hacia finales de época neroniana. Por lo que se refiere a la cuarta cremación, la urna presentaba características morfológicas propiamente romanas, con el borde acanalado al exterior (Cánovas et al. 2006: 291). El contenedor cinerario estaba acompañado por dos lucernas de disco, posiblemente Dressel 11, un plato en terra sigillata hispánica, una orcita, un plato-tapadera, un jarro y una cantimplora, que han llevado a situarla entre época neroniana y flavia. Por último, encontramos una cremación en urna de cerámica de cierto gusto indígena con la base en umbo, pero sin decoración de bandas (Cánovas et al. 2006: 291), que apareció acompañada de una botella, un cuenco y una tapadera, que la sitúan hacia finales del s. I o principios del s. II d.C.

\section{PLAN ESPECIAL MANZANA BANESTO (AVDA. CRUZ DE JUÁREZ) (fig. 2, 5)}

En este solar de grandes dimensiones, ubicado en la zona septentrional de la ciudad, junto a los restos de una villa suburbana de época bajoimperial, fue posible documentar una necrópolis con un total de 33 tumbas de cremación adscritas al s. I d.C. (Salinas Villegas 2004). El sepulcretum contaba como elemento protagonista con un recinto funerario de planta cuadrangular con un único enterramiento en su interior. El resto de tumbas, de carácter sencillo, se encontraban dispersas en torno al recinto funerario y en la zona nororiental del solar, identificándose cinco enterramientos primarios o busta (Tumbas 1, 4, 6, 16 y 18), siete tumbas denominadas como ustrinum (Tumbas 2, 9, 10, 11, 12, 14 y 22) y cuatro enterramientos secundarios (Tumbas 5, 7, 13 y 24), además de tres quemaderos reutilizados como lugar de enterramiento en un momento posterior (Tumbas 3,8 y 10). 
Por lo que se refiere a las urnas de tradición indígena, tema central de nuestro trabajo, se localizaron cinco ejemplares:

- Tumba 3. Bustum. Urna de tradición indígena identificada con el Tipo V de B. García Matamala. De gran tamaño y forma ovoide con unas dimensiones de $21 \mathrm{~cm}$ de altura y $19 \mathrm{~cm}$ de diámetro. Presenta borde exvasado y ónfalo marcado (base hundida). De la zona central del galbo parten dos amplias asas geminadas. Cuenta con una decoración a base de líneas horizontales de color vinoso dispuestas de la siguiente manera: una en la parte inferior del galbo, cuatro en la parte superior y, por último, una línea en el borde del labio. El ajuar estaba compuesto por tres cubiletes de paredes finas decorados a la barbotina, fragmentos de tres ungüentarios de vidrio, tres copas, un plato de cerámica Peñaflor y dos clavos.

- Tumba 5. Cremación secundaria en hoyo. Urna de tradición indígena con características semejantes a la anterior, aunque sin presencia de ajuar.

- Tumba 7. Cremación secundaria en hoyo. Urna de tradición indígena correspondiente con el Tipo III de B. García Matamala, con un diámetro pequeño en la base ( 8 $\mathrm{cm})$ que se va ensanchando en altura hasta alcanzar los $28 \mathrm{~cm}$ de diámetro máximo.

- Tumba 8. Bustum. Urna de tradición indígena imposible de identificar con ningún tipo dada su fragmentación, aunque las asas podrían indicar su equivalencia con el Tipo IV de B. García Matamala. Como parte del ajuar contaba con nueve piezas de vajilla Peñaflor (tres platos, tres cuencos y tres tacitas), dos ungüentarios de cerámica y uno de vidrio, una lucerna decorada con la cabeza del dios Pan y varios clavos. También se encontraron restos de ungüentarios de vidrio, deformados y rotos.

- Tumba 10. Bustum. Urna de tradición indígena que podría pertenecer al Tipo V de B. García Matamala, aunque el mal estado de conservación impide asegurarlo, acompañada por nueve piezas de vajilla Peñaflor (tres platos, tres cuencos y tres tacitas), además de una placa de pizarra con los bordes biselados.

\section{CALLE PINTOR RACIONERO CASTRO (fig. 2, 6)}

Aunque la subestación eléctrica de la Compañía Sevillana había alterado bastante la estratigrafía de este lugar, fue posible identificar una fase correspondiente a una necrópolis de época altoimperial compuesta por cinco tumbas de cremación (Cano 2003): dos de carácter primario (Tumbas 3 y 5), dos de carácter secundario (Tumbas 1 y 2) y otra más (Tumba 4) que presenta problemas de interpretación debido a su mal estado de conservación. Así las cosas, se pudieron recuperar un total de dos urnas cinerarias:

- Tumba 1: cremación secundaria en fosa rectangular en cuyo interior, concretamente en la esquina SO, se dispuso una urna de tradición indígena (Tipo III de B. García Matamala), que contenía restos muy fragmentados de la cremación, así como parte de un platito que habría servido como tapadera. Por su parte, en la esquina NO se había depositado un ungüentario de vidrio globular con cuello desarrollado y borde exvasado verde-azulado, y un vaso también de vidrio con asa, cubierto con un plato de cerámica común con el borde engobado en blanco dispuesto boca abajo. Este último vaso de vidrio, similar a una píxide, contenía restos óseos calcinados. La tumba quedó cubierta por dos capas de piedras de calcarenita trabadas con arcilla.

- Tumba 5: cremación primaria (bustum) en fosa cuadrangular con esquinas redondeadas. Parece ser que una vez realizada la combustión se retiraron los restos de cenizas y fragmentos óseos (muy fragmentados) y se introdujeron en una urna cineraria de tradición indígena (Tipo V de B. García Matamala). Sobre la olla se dispuso un platito de cerámica como tapadera y sobre éste una piedra de caliza. Acompañaban al enterramiento una botellita de cerámica común, de pasta clara anaranjada, un pequeño ungüentario de vidrio y un vasito de vidrio azulado. Igualmente, en el estrato de relleno de la fosa aparecieron restos de vidrio calcinado y retorcido, restos óseos humanos calcinados y restos de, al menos, tres ungüentarios de cerámica (uno de ellos completo) y de terra sigillata itálica.

Los ajuares ofrecen una cronología centrada en la primera mitad del s. I d.C., al igual que los materiales que se recogieron durante la excavación del estrato de matriz arcillosa que cubría todas las tumbas, sellando así el uso de la necrópolis en este momento.

\section{CALLE PINTOR PALOMINO (fig. 2, 7)}

En la Cata I se detectó un amontonamiento de cerámica, más o menos sellado por fragmentos de tegulae y ánforas, que ante la ausencia de cualquier tipo de estructura fueron interpretados como los restos de una sepultura de cremación, acompañada de un repertorio relativamente amplio de cerámica campaniense, algo de cerámica romana común y fragmentos de una o varias ánforas de difícil adscripción tipológica (López Palomo 2003). 
Entre el material recogido destaca el fragmento del borde de una urna de labio vuelto al exterior, con decoración interior y exterior a base de bandas de color ocre, que podría identificarse con el Tipo II o III de B. García Matamala. También aparecieron dos fragmentos de platos de carena alta y labio saliente. Por último, formando parte del ajuar se recuperó parte de una gran pátera de cerámica gris que imita la forma de algunos platos de origen campaniense, aunque con reminiscencias indígenas. Todo este material nos sitúa en la primera mitad del s. I d.C.

\section{AVENIDA LLANOS DEL PRETORIO (fig. 2, 8)}

A continuación, nos centraremos en el análisis del conjunto de urnas documentadas en la necrópolis de Llanos del Pretorio, un nuevo sector de la necrópolis septentrional hallado durante la realización de un Seguimiento Arqueológico (Rubio 2019). En este sepulcretum se ha documentado el conjunto más numeroso de urnas cinerarias cordubenses contextualizadas, la mayor parte de tradición indígena, convirtiéndose en un caso paradigmático a partir del cual extraer nuevas e interesantes conclusiones sobre el tema, especialmente, por la metodología de excavación y su posterior estudio en laboratorio a cargo de un equipo multidisciplinar (Vaquerizo et al. 2019: 79-105; 2020). En este sector de necrópolis, articulado en torno a varias vías funerarias, se documentaron un total de 15 recintos funerarios, en cuyo interior se dispusieron los diferentes enterramientos (fig. 3), tanto de cremación como de inhumación. Estos últimos siempre de categoría infantil. En total, se recuperaron 67 enterramientos repartidos de la siguiente forma: 50 cremaciones (dos de ellas dobles, con dos urnas cada una), 11 inhumaciones perinatales, dos enterramientos de sendos perros, dos posibles cremaciones, y dos posibles inhumaciones, todas ellas realizadas entre principios y el tercer cuarto del s. I d.C.

Centrándonos en los contenedores funerarios cerámicos, estos se usaron tanto para cremaciones como para inhumaciones perinatales. Estas últimas (Enterramientos 5, 34 y 40) usaron siempre urnas del Tipo V de B. García Matamala. Por su parte, las cremaciones se distribuyen

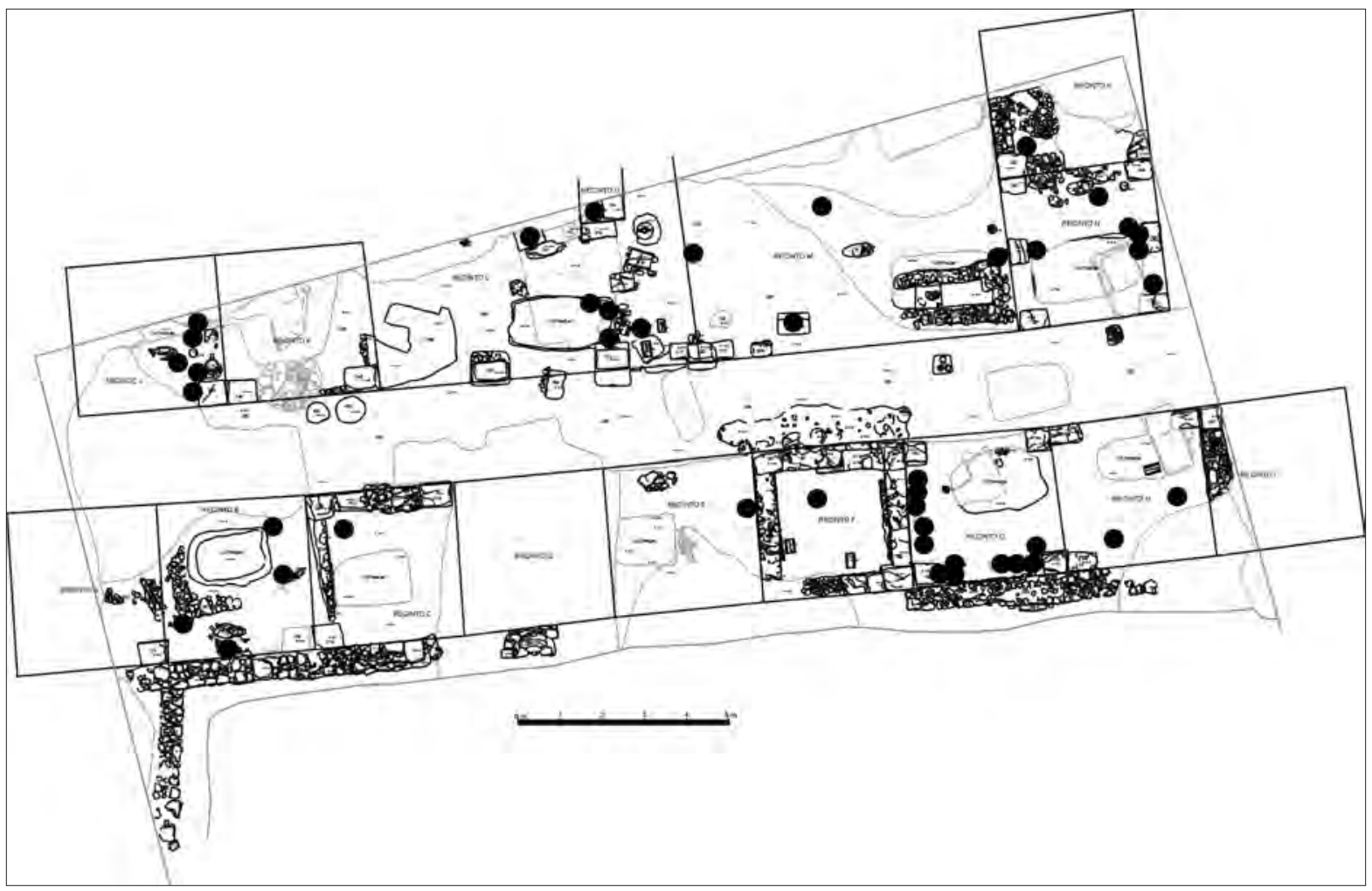

Fig. 3: Planimetría de la necrópolis de Llanos del Pretorio con indicación de los hallazgos correspondientes con urnas de tradición indígena. Elaboración propia. 
entre urnas de cerámica de tradición indígena (43) y urnas de cerámica común, de cocción tanto oxidante como reductora (seis). Debido a la acción de las alteraciones post-deposicionales sobre algunas de las urnas de tradición indígena, que apenas han conservado la base, resulta complejo definir su tipología. Aun así, hemos intentado hacer una asignación provisional, siguiendo los parámetros establecidos por B. García Matamala (2002-2003), que resumimos a continuación:

- Tipo II: se han documentado un total de 15 ejemplares (Enterramientos 10, 11, 12, 14, 15, 16, 30, 46-A, 48, $53,55,56,58,66$ y 67 ) de los que cabe destacar la ausencia total de asas. Todas comparten forma, decoración a base de bandas de color ocre y tipo pasta de tono claro. Con respecto a los bordes, la mayoría los presentan engrosados, siendo sólo dos las que lo tienen vuelto (Enterramientos 10 y 48). Sus medidas oscilan entre los 18 y los $19,1 \mathrm{~cm}$ de diámetro máximo, y entre los 22 y los $26 \mathrm{~cm}$ de altura. Con respecto a las tipologías de enterramientos en las que aparecen, la fosa simple es el predilecto, con algunas variantes dependiendo del tipo de materiales con los que se proteja la urna, con un pequeño fragmento de ánfora, con un cuerpo de ánfora o con restos de mampostería.

- Tipo III: hemos documentado ocho ejemplares, lo que constituye un salto cualitativo muy importante con respecto al estudio de B. García Matamala (2001), donde apenas se analizaban un par de ejemplares. Nos referimos a los Enterramientos 2, 7, 23, 26, 27-A, 29, 46-B y 54, en los que se distinguen dos tipos de pastas: claras y anaranjadas. Para que la decoración a base de bandas de tono ocre fuera apreciable cuentan con un engobe blanquecino que se aplicaba de forma previa. Dentro de este grupo existen importantes diferencias en cuanto al tamaño: con alturas que oscilan entre los $15 \mathrm{~cm}$ y $\operatorname{los} 27 \mathrm{~cm}$, con una media de 18-22 cm; y diámetros máximos que van de los 5,09 a los $7 \mathrm{~cm}$, situándose la media entre 17,19 y 19,79 $\mathrm{cm}$. Atendiendo a la tipología de enterramientos en los que aparece este tipo de urnas, al igual que en el tipo anterior, la fosa simple es el tipo mayoritario, también con diferencias en el tipo de elementos que protegían las urnas: cuerpos de ánforas o restos de mampostería.

- Tipo IV: se han documentado un total de siete ejemplares, sin duda el más escaso. Pese a que la muestra es pequeña, las características de las urnas localizadas nos llevan a plantear la existencia de dos subtipos, a saber:

- Subtipo IV-A (Enterramientos 6 y 21): urnas de perfil globular, de pequeño tamaño y con dos asas en la zona central del galbo, que presentan base plana y borde recto. Este tipo de borde impone el uso de un tipo determinado de tapadera, los denominados cuencos-tapadera. Con respecto a la decoración, presentan un engobe blanco sobre el que se disponen diferentes bandas de color ocre. Su altura oscila entre los 16-17 $\mathrm{cm}$, mientras que sus diámetros máximos van desde $\operatorname{los} 7$ a los 17,83 cm. En cuanto a la tipología de enterramientos en los que aparecen, siempre son fosas simples en las que las urnas aparecen protegidas con cuerpos de ánfora.

- Subtipo IV-B (Enterramiento 1 y 31): urnas de perfil globular, de pequeño tamaño y con dos asas en la zona central del galbo, que presentan un pie marcado o ligeramente marcado y borde exvasado. Con respecto a la decoración, presentan un engobe blanco sobre el que se disponen bandas de color ocre. De especial relevancia es la urna perteneciente al Enterramiento 1 , a base de varios semicírculos concéntricos, una decoración bastante arcaizante. La altura de las urnas de este tipo va desde los 16 a los $19 \mathrm{~cm}$, y sus diámetros máximos oscilan entre los 7,32 y los $19,42 \mathrm{~cm}$. Este tipo de urnas siempre aparecen en fosas simples sin ningún tipo de protección.

- Tipo V: contamos con diez ejemplares identificados con los Enterramientos 5, 24, 25, 27-B, 28, 34, 40, 47, 57 y 62. Todas las urnas comparten forma, decoración a base de bandas de color ocre y tipo de pasta de tono claro, diferenciándose solamente en su tamaño, con alturas que oscilan entre los 22 y los $34 \mathrm{~cm}$, y diámetros máximos que van desde los 19,1 a los 27,07 cm. Como ya apuntábamos anteriormente, es el único tipo en el que se han documentado inhumaciones perinatales, ya que por su tamaño son las idóneas para acoger ese tipo de enterramientos. Estas inhumaciones infantiles siempre aparecen depositadas en fosas simples sin ningún elemento que proteja las urnas, mientras que las usadas para albergar cremaciones cuentan con restos de mampostería como cubierta e, incluso, un lebrillo colocado boca abajo, caso del Enterramiento 47.

\section{CALLE HÉROES DE CHERNÓBIL (fig. 2, 9)}

La excavación arqueológica en este sector de la necrópolis nororiental, vinculada a una calzada supuestamente fosilizada en la avenida de las Ollerías, puso al descubierto una dilatada ocupación de este solar que arrancaba con la presencia de algunos enterramientos vinculados a época tardorrepublicana (López Jiménez 2006; 2009; Ruiz Osuna 2007b: 25-40; Vaquerizo y 
Sánchez 2008: 101-131). Estos hacen referencia a cremaciones aisladas y dispersas en fosa simple, mientras que en época altoimperial asistimos a la planificación topográfica del espacio funerario a base de vías secundarias (seguramente funerarias) y varios recintos dispuestos en batería, con medidas estandarizadas que oscilan entre los 12 y 15 pies romanos. Precisamente, en el interior de uno de estos recintos funerarios (Recinto 6) fueron localizadas las Tumbas 34, 35, 37, 41 y 42. Excepto la 35 (inhumación sobre tegulae), las demás eran cremaciones. Lo interesante es que se recuperaron dos urnas de tradición indígena que estaban depositadas directamente sobre el terreno, sin ningún tipo de cubrición. Se trata de dos urnas con tendencia globular y base con ónfalo central, con decoración a base de franjas paralelas de color ocre, que podemos identificar (sólo por observación fotográfica) con el Tipo II de B. García Matamala. Por último, haremos referencia a otra urna de tradición indígena que formaba parte de la Tumba 43. No hay referencia a ella en el texto del informe ni en las diferentes planimetrías; sin embargo, aparece recogida en la documentación gráfica, lo que nos lleva a interpretarla como un posible Tipo IV de B. García Matamala.

\section{ACTUALIZACIÓN TIPOLÓGICO-CRONOLÓGICA}

La recopilación y revisión documental de todas las urnas de tradición indígena en ámbito funerario halladas en Corduba - Colonia Patricia hasta la fecha han permitido llevar a cabo una actualización de datos y una ampliación tipológica, siendo posible, además, atisbar determinadas pautas cronológicas que comentaremos a lo largo de este apartado. Para empezar, la estadística pone de
Fig. 4: Tabla de dispersión de ollae ossuariae (N.M.I.) procedentes de Córdoba. Elaboración propia.

\begin{tabular}{|c|c|c|c|c|c|}
\hline NECRÓPOLIS & $\begin{array}{l}\text { Cerámica } \\
\text { Tradición } \\
\text { Indígena }\end{array}$ & $\begin{array}{l}\text { Cerámica } \\
\text { Común }\end{array}$ & Vidrio & Caliza & Terracota \\
\hline Calle Adarve & 1 & - & - & - & - \\
\hline La Constancia & 3 & 4 & 7 & 4 & 1 \\
\hline Calle Muñices & 5 & - & - & 2 & - \\
\hline Manzana Banesto & 5 & - & 1 & 4 & - \\
\hline Beatriz Enriquez & 19 & - & 1 & 1 & - \\
\hline Camino Viejo Almodovar & 14 & - & - & - & - \\
\hline El Avellano, 12 & 3 & - & 1 & - & - \\
\hline C/Héroes de Chernóbil & 3 & - & 2 & - & - \\
\hline Antonio Maura, 10 & 2 & - & - & 2 & - \\
\hline Cercadilla & 1 & - & - & - & - \\
\hline Ollerias, 14 & 1 & . & - & - & 1 \\
\hline Ronda de los Tejares, 6 & 1 & - & - & - & - \\
\hline La Bodega $S / N$ & 1 & - & - & - & - \\
\hline Abderramán 111,10 & - & - & - & 1 & - \\
\hline Glorieta Ibn Zaydun & - & - & 4 & 1 & - \\
\hline Llanos del Pretorio & 46 & 3 & 1 & 5 & - \\
\hline Pintor Racionero Castro & 3 & - & 1 & 1 & - \\
\hline Pintor Palomino, 1 & 1 & - & - & - & - \\
\hline Avenida del Corregidor & 1 & 5 & 1 & - & - \\
\hline $\begin{array}{l}\text { Sede EMACSA (Llanos del } \\
\text { Pretorio) }\end{array}$ & 3 & 3 & - & - & - \\
\hline Viaducto del Pretorio & 1 & - & - & - & - \\
\hline $\begin{array}{l}\text { Red Arterial Ferroviaria de } \\
\text { Córdoba }\end{array}$ & 1 & - & - & - & - \\
\hline Calle Abéjar & 1 & - & - & - & - \\
\hline Seguimiento Plan Renfe & 1 & - & - & - & - \\
\hline TOTAL (N.M.I.) & 117 & 14 & 19 & 21 & 2 \\
\hline
\end{tabular}


manifiesto que las urnas de tradición indígena fueron, sin duda, el contenedor cinerario elegido por la mayoría de la población cordobesa de época romana época altoimperial, seguidas, con gran diferencia, por las urnas de vidrio y de caliza (fig. 4). Así pues, en apenas dos décadas hemos pasado de una treintena de ejemplares a 117 , y lo más importante, hemos podido confirmar y ampliar mínimamente (con un tipo y un subtipo) las tipologías establecidas hasta el momento, configurando una nueva propuesta clasificatoria (fig. 5):

- Tipo I: urnas de tendencia globular con borde exvasado, cuello estrangulado prácticamente inexistente, y base con ónfalo. Se caracterizan por la presencia de decoración a base de franjas paralelas que enmarcan líneas verticales con ondulaciones de color ocre. El único ejemplar de esta tipología, ya recogido por B. García Matamala, presentaba un diámetro de $14 \mathrm{~cm}$ y una altura de $19 \mathrm{~cm}$.

- Tipo II: urnas con borde vuelto o engrosado, cuello desarrollado con forma acampanada, galbo bitroncocónico con tendencia globular y base con pie marcado y ónfalo central. Presentan una decoración con franjas horizontales paralelas de diferentes anchuras y color ocre que se disponen en el cuello las de menor amplitud y en el centro del galbo la más ancha, enmarcada por una o dos líneas más finas. Sus dimensiones oscilan entre los 14 y 16 $\mathrm{cm}$ de diámetro y su altura entre 22 y $25 \mathrm{~cm}$. B. García

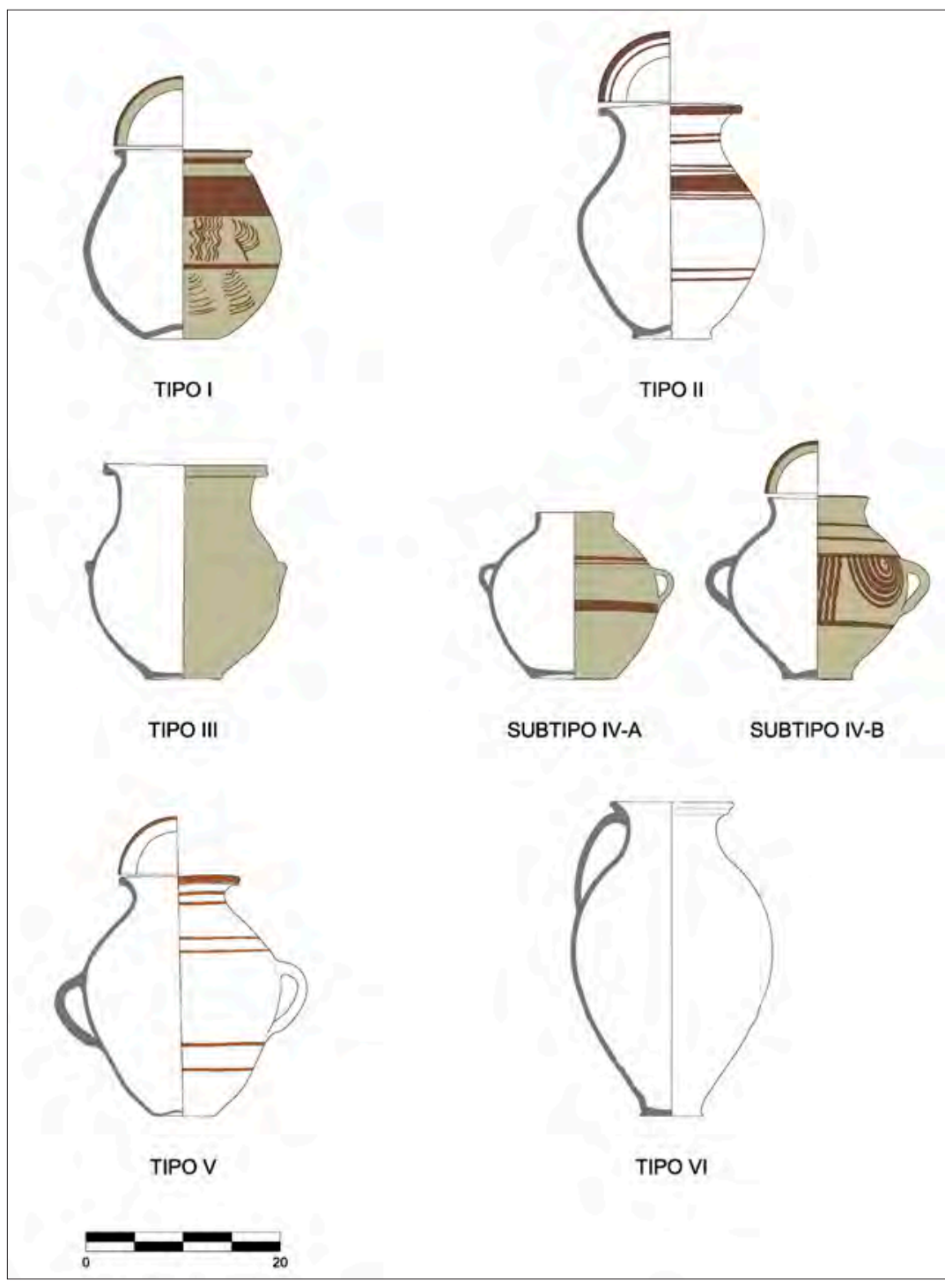

Fig. 5: Clasificación tipológica de urnas de tradición indígena en Córdoba (Dibujo: J. M. Tamajón). 
Matamala identificó un total de cuatro urnas de esta tipología, procedentes del Seguimiento del Plan Renfe y tres del Camino Viejo de Almodóvar. A éstas debemos sumarles, con seguridad, doce urnas de Llanos del Pretorio (Enterramientos 10, 12, 15, 16, 30, 46-A, 48, 53, 55, 56, 58 y 66), la urna del bustum de Calle Muñices, la urna de la Tumba 41 de Héroes de Chernóbil, y la de la Tumba 24.1 de La Constancia.

- Tipo III: urnas bitroncocónicas con el borde engrosado y dos asas simuladas en el centro del galbo. Se caracterizan por tener la base plana o un pie ligeramente marcado. No obstante, la decoración se simplifica respecto a la tipología anterior pues se reduce el número de bandas horizontales de color ocre. $15,5 \mathrm{~cm}$ de diámetro y 23,5 cm de altura. B. García Matamala apenas contaba con un par de ejemplares de esta tipología, procedentes de un monumento funerario de calle La Bodega y de la necrópolis de Camino Viejo de Almodóvar. A esas dos debemos sumarle nueve ejemplares procedentes de Llanos del Pretorio (Enterramientos 2, 7, 23, 26, 27-A, 29, 46-B, 54 y 60), la urna de la Tumba 7 de Manzana Banesto, la de la Tumba 11 de Avda. de las Ollerías, la urna de la Tumba 1 de la calle Pintor Racionero Castro, y las urnas identificadas con las UUEE 108 y 126 de la calle Beatriz Enríquez.

- Tipo IV: urnas de perfil globular de pequeño tamaño con unas dimensiones que oscilan entre $7,5 \mathrm{~cm}$ y $10 \mathrm{~cm}$ de diámetro y una altura entre 13,5 y $16 \mathrm{~cm}$. Presentan dos asas en el centro del galbo y base plana con el pie ligeramente indicado. En su trabajo, B. García Matamala adscribió a este tipo cuatro ejemplares procedentes del Camino Viejo de Almodóvar. Por nuestra parte, planteamos la existencia de dos subtipos en función del borde que presentan:

- Subtipo IV-A: urnas de perfil globular, de pequeño tamaño y con dos asas en la zona central del galbo, con unas dimensiones que oscilan entre $7 \mathrm{~cm}$ y $17,83 \mathrm{~cm}$ de diámetro y una altura entre $16 \mathrm{~cm}$ y $17 \mathrm{~cm}$. Presentan base plana y borde recto, que impone el uso de un tipo determinado de tapadera, los denominados cuencos-tapadera, que se acoplan perfectamente al mismo. Con respecto a la decoración, presentan un engobe blanco sobre el que se disponen diferentes bandas de color ocre. A este tipo se adscribirían las urnas de las Tumbas 6 y 21 de Llanos del Pretorio, tres urnas del Camino Viejo de Almodóvar (urnas 6241, 6553 y 6563) y la urna de la calle Adarve.
- Subtipo IV-B: urnas de perfil globular, de pequeño tamaño y con dos asas en la zona central del galbo, con unas dimensiones que oscilan entre 7,2 cm y 19,42 cm de diámetro y una altura entre $16 \mathrm{~cm}$ y $19 \mathrm{~cm}$. Presentan un pie marcado o ligeramente marcado y borde exvasado. Con respecto a la decoración, presentan un engobe blanco sobre el que se disponen bandas o semicírculos de color ocre, un tipo de decoración bastante arcaizante. Se adscriben a este tipo las urnas de las Tumbas 1 y 31 de Llanos del Pretorio, y una urna del Camino Viejo de Almodóvar (urna 6562).

- Tipo V: urnas de gran tamaño, con diámetro entre 15 y $18 \mathrm{~cm}$ y una altura de $30-33 \mathrm{~cm}$. Presentan el borde exvasado, galbo de forma ovoide y ónfalo marcado. De la zona central del galbo parten amplias asas geminadas. $\mathrm{Su}$ decoración se basa en finas líneas horizontales de color vinoso en el cuello y en la parte superior e inferior del galbo. B. García Matamala adscribió 11 ejemplares a este tipo, procedentes de Cercadilla, cinco del Camino Viejo de Almodóvar, tres de calle El Avellano y dos de la necrópolis excavada en la antigua fábrica "La Constancia", a los que se suman los cuatro ejemplares de la calle Muñices que publicó con posterioridad. Ahora contabilizamos ocho ejemplares de Llanos del Pretorio (Enterramientos 5, 24, 25, 27-B, 28, 34, 40 y 47), tres de la Manzana Banesto (Tumbas 3, 5 y 10), uno de Ronda de los Tejares y otra más correspondiente con la Tumba 5 del sector funerario excavado en la calle Pintor Racionero Castro.

- Tipo VI: urnas con borde engrosado, cuello desarrollado con forma acampanada, galbo bitroncocónico con tendencia globular y base con pie marcado. Poseen una única asa de grandes dimensiones que arranca desde el borde y se desarrolla hasta el centro del galbo. En principio no presentan decoración, aunque es un extremo a constatar puesto que apenas contamos con dos ejemplares, y uno de ellos solo se conserva parcialmente. A este nuevo tipo se adscribe la urna de la Cremación 3 del bustum-ustrinum de la Sede de EMACSA y la urna UE 51 de la calle Beatriz Enríquez.

El crecimiento experimentado en el repertorio de urnas de tradición indígena nos permite aproximarnos un poco más a sus cronologías (fig. 6), especialmente, gracias a la presencia de algunos ajuares bastante complejos que se han prestado a datación. Así, para el s I a.C. contamos con la aparición del Tipo I, el más arcaizante de todos, mientras que para finales de esa misma centuria lo 


\begin{tabular}{|c|c|c|c|c|c|c|c|c|}
\hline & s. I a.C. & Fin. s. I a.C. & $1^{\mathrm{a}} 1 / 2 \mathrm{~s}$. I d.C. & Tiberio & Claudio & Nerón & $2^{a} 1 / 2$ s. I d.C. & s. II d.C. \\
\hline TIPO I & 0 & & & & & & & \\
\hline TIPO II & & 0 & 0 & 0 & 0 & 0 & & \\
\hline TIPO III & & & 0 & 0 & 0 & 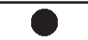 & 0 & 0 \\
\hline TIPO IVa & & & & & 0 & & & \\
\hline TIPO IVl & & & & & & 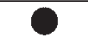 & & \\
\hline TIPO V & & & 0 & 0 & 0 & 0 & 0 & 0 \\
\hline TIPO VI & & & ? & & & & & \\
\hline
\end{tabular}

Fig. 6: Tabla tipo-cronológica de las urnas cinerarias de tradición indígena de Córdoba. Elaboración propia.

haría el Tipo II. La primera mitad del s. I d.C. estará protagonizada por la continuidad del Tipo II y la aparición de los Tipos III, V y VI, siendo el primero de ellos el más abundante. Para los años centrales del s. I d.C. observamos un uso más pronunciado del Tipo $\mathrm{V}$ con ocho ejemplos. Llegados a este punto, creemos necesario acercarnos de forma detallada a los resultados derivados de la necrópolis de Llanos del Pretorio, que, aunque datada de forma global en fechas tiberio-neronianas, es la única que nos permite establecer varias fases de uso, aportando una cronología relativa basada en la estratigrafía de los recintos funerarios y los ustrina (Ruiz Osuna 2020: 91-104). Así, en la primera fase de la necrópolis nos encontramos con cinco urnas del Tipo II y cuatro del Tipo III, que ya habían hecho acto de aparición en época augustea. Estas mismas continúan siendo habituales en la siguiente fase con tres ejemplares del Tipo II y dos del Tipo III, a las que se suman ahora dos urnas del Tipo IVa, que hace acto de aparición por primera vez. Para la tercera y última fase de vida de la necrópolis vemos que el Tipo II desaparece, el Tipo III se mantiene con dos nuevos casos y se introduce el Tipo IVb. Pasados los años centrales del s. I d.C. vemos como los Tipos III y $\mathrm{V}$ son los únicos que continúan, llegando incluso a inicios del s. II d.C.

De igual forma, la contextualización de los hallazgos más recientes nos ha permitido completar las tipologías de enterramientos ofrecidas por B. García Matamala, según la posición de las urnas en la tumba y las características formales de ésta, quedando de la siguiente forma (fig. 7):

- Tipo I: Enterramientos con urnas de tradición ibérica en fosa simple sin ningún tipo de elemento que las proteja.

- Subtipo Ia. Con la urna en posición vertical: se trata del tipo de enterramiento más usual, documentado en un total de 28 ocasiones. Destacan los 17 enterramientos de Llanos del Pretorio (Enterramientos $1,3,4,5,7,8,9,14,16,31,34,40,49,53,62,63$ y 66), las Tumbas A, C, D de Calle Muñices; así como las Tumbas 5 y 7 de la Manzana Banesto. La Tumba VII de El Avellano, las Tumbas 42 y 43 de Héroes de Chernóbil, la tumba de Cercadilla, la Tumba 1 de Pintor Racionero Castro y la tumba de la Calle Adarve.

- Subtipo Ib. Con la urna posición invertida: un par de enterramientos se adscriben a este subtipo, la Tumba B de Calle Muñices y la Tumba VIII de El Avellano.

- Tipo II: Enterramientos con urnas de tradición ibérica en fosa simple con un recipiente o recipientes cubriéndolas.

- Subtipo IIa. Con un recipiente: documentado en 15 tumbas de Llanos del Pretorio (Enterramientos 6, $10,11,12,15,21,25,26,30,35,45,47,48,54$ y 55), en la Tumba V de El Avellano, en la Tumba 2 de Pintor Racionero Castro y en las urnas UE 42 de Beatriz Enríquez y UE 49 de Antonio Maura.

- Subtipo IIb. Con varios recipientes: tan solo documentado en una tumba de Pintor Palomino.

- Subtipo IIc. En posición invertida con un recipiente: al igual que en el caso anterior, documentado en una única ocasión, en el Seguimiento de la Red Arterial Ferroviaria de Córdoba.

- Subtipo IId. Enterramiento doble con recipiente sobre una de las urnas: documentado en el Enterramiento 46 de Llanos del Pretorio.

- Tipo III: Enterramientos con urnas de tradición ibérica en fosa simple con presencia de tegulae

- Subtipo IIIa. Con tegulae en posición horizontal bajo la urna: documentado en un par de ocasiones, en la Tumba 24.1 de La Constancia y en una tumba del entorno del viaducto del Pretorio.

- Subtipo IIIb. Con varias tegulae en posición vertical a modo de cista: documentado en la Tumba 5 de La Constancia.

- Subtipo IIIc. Con cubierta de tegulae alla capuccina: uno de los enterramientos del Camino Viejo de Almodóvar seguía esta tipología. 


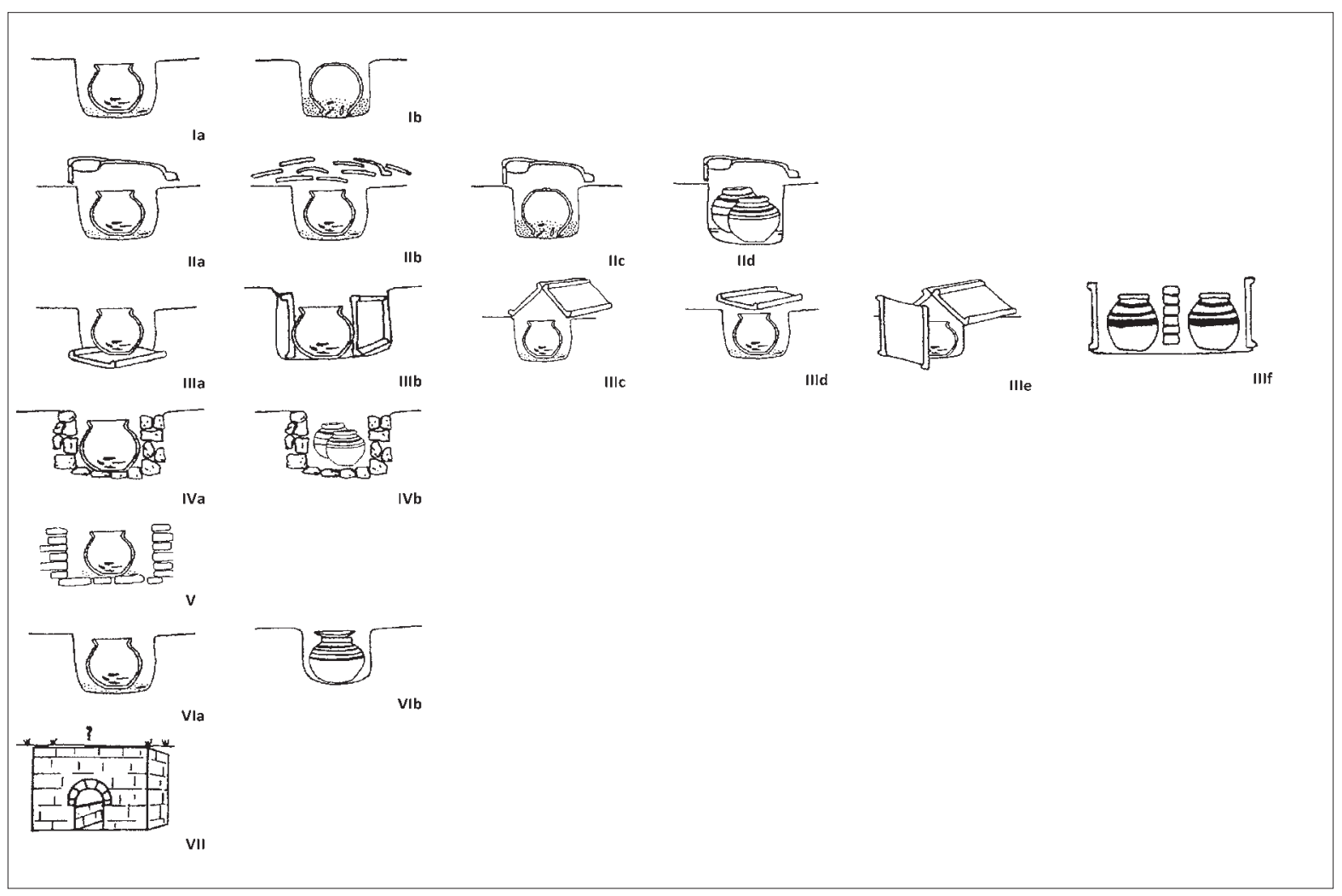

Fig. 7: Tipología de enterramientos con presencia de urnas de tradición indígena en Córdoba. Elaboración propia.

- Subtipo IIId. Con cubierta de un fragmento de tegula: documentado en la Tumba 60 de Llanos del Pretorio.

- Subtipo IIIe. Con una tegula en posición vertical y cubierta de tegulae alla capuccina: documentado en la Tumba 11 de Ollerías.

- Subtipo IIIf. Enterramiento doble con los extremos marcados con tegulae en posición vertical y un muro de opus latericium: La Tumba 18.3 de La Constancia pertenecía a esta tipología.

- Tipo IV: Enterramientos con urnas de tradición ibérica en fosa simple con cista de mampostería.

- Subtipo IVa. Enterramiento individual con cista de mampostería: documentado en siete tumbas de Llanos del Pretorio (Enterramientos 2, 24, 28, 29, 56, 57 y 58) y en la Tumba 41 de Héroes de Chernóbil.

- Subtipo IVb. Enterramiento doble con cista de mampostería: documentado en el Enterramiento 27 de Llanos del Pretorio.

- Tipo V: Enterramientos con urnas de tradición ibérica en fosa simple con estructura de ladrillo. Un único caso documentado en la Tumba 67 de Avenida del Corregidor.
- Tipo VI: Enterramientos con urnas de tradición ibérica en busta.

- Subtipo VIa. En bustum: documentado en 15 busta de Beatriz Enríquez (UUEE 20, 51, 54, 62, 75, $78,90,93,108,122,126,140,161,194$ y 203), en el bustum de Calle Muñices, en las Tumbas 3, 8 y 10 de la Manzana Banesto, en la Tumba 5 de Pintor Racionero Castro, y en las cremaciones 1, 3 y 5 del bustumustrinum de la Sede de EMACSA.

- Subtipo VIb. En bustum con dos recipientes sobre la urna: documentado en la tumba de Ronda de los Tejares.

- Tipo VII: Enterramientos con urnas de tradición ibérica en un monumento funerario. Un único caso documentado en el monumento funerario de Calle La Bodega.

Con respecto a las cuestiones cronológicas, B. García Matamala (2002-2003: 260) apuntaba en sus trabajos que las estructuras más simples serían las más tempranas y que se desarrollarían hasta finales de época republicana, mientras que las que utilizan las tegulae en su construcción o cubierta podrían alcanzar los comedios del s. I d.C., llegando en algunos casos hasta comienzos del s. II 
d.C. La revisión y actualización de las tipologías de enterramientos vinculadas a urnas de tradición indígena que hemos presentado aquí confirma y amplía estos supuestos, pudiendo aportar algo más de información en algunos casos. Así, la estructura funeraria más utilizada es, sin duda, la fosa simple sin ningún tipo de cubierta con 33 ejemplos, seguida de los busta en fosa simple con 24 casos. A continuación, destacan las fosas simples que utilizan como cubierta uno o varios recipientes, con un total de 20. Por su parte, hemos localizado diez tumbas realizadas en cista de mampostería y seis fosas simples con cubiertas de tegulae. Por último, la cista de ladrillo y el monumento funerario aparecen en una sola ocasión.

En cuanto a la distribución cronológica, para finales del s. I a.C. y principios del s. I d.C. contamos con dos enterramientos del Tipo I (fosa simple), uno del Tipo IV (cista de ladrillo) y otro del Tipo VII (monumento funerario). Durante la primera mitad del s. I d.C. seguimos observando la aparición de urnas de tradición indígena en fosa simple sin cubierta, pero también lo hacen las fosas simples con cubierta de recipientes cerámicos y los busta. Conforme nos acercamos a mediados del s. I d.C. el número de casos y de tipologías aumenta, tal como ponen de manifiesto las 20 fosas simples sin cubierta, las 15 fosas simples con cubierta de recipientes cerámicos, las cuatro fosas simples con cubiertas de tegulae, las nueve cistas de mampostería y los 16 busta, poniendo de manifiesto un auge de la cremación como principal rito de enterramiento. A finales del s. I d.C. o principios del s. II d.C. podemos adscribir cuatro tumbas realizadas en fosa simple, dos más en fosa simple con cubierta de recipientes cerámicos, otras dos con cubierta de tegulae y un bustum, lo que pone de manifiesto un descenso importante en el uso de urnas de tradición indígena para el cambio de siglo, coincidiendo en general con el aumento de las urnas de piedra caliza, de vidrio o de cerámica común.

Por último, no quisiéramos dejar de lado el estudio de los ajuares que han aparecido como acompañamiento de las urnas de tradición indígena y que no sólo han servido para acotar cronologías, sino para conocer con más detalle las costumbres y rituales vinculados a este tipo de enterramientos. Aun así, a pesar del incremento de casos, resulta imposible establecer un criterio que determine la presencia/ausencia de ajuares junto a urnas de este tipo, extensible también al resto de enterramientos de la época. Tampoco ha sido posible establecer la relación entre la elección de un tipo determinado de urna y un ajuar específico, no existiendo un criterio unificado, aunque sí unas características similares dentro de cada sector funerario. Así, por ejemplo, en la necrópolis excavada en la calle Pintor Racionero Castro nos encontramos con una asociación clara entre ungüentario y vaso de vidrio, que no aparece, de momento, en ningún otro espacio funerario. Por su parte, en la Manzana Banesto es el uso de las cerámicas del tipo Peñaflor el que se impone en todos los enterramientos que cuentan con urnas de tradición indígena, vinculándose al ajuar-tipo definido hace años para las necrópolis cordubenses (Vargas 2002: 297-310). Por el contrario, las lucernas se convierten en las auténticas protagonistas en el caso de la necrópolis de la calle Beatriz Enríquez, próxima a la anterior, al igual que el sepulcretum de Llanos del Pretorio donde, sin embargo, los ungüentarios de vidrio se alzan como el elemento más recurrente, apareciendo en 15 de los 23 enterramientos realizados en urnas de tradición indígena que contaban con depósito ritual.

Todo ello podría poner de manifiesto que el material elegido como ajuar funerario, al menos el que no hace referencia a elementos de uso personal, no dependería tanto de la adscripción étnica o cultural ni de ciertas costumbres de tipo ancestral o posibles creencias religiosas, sino más bien de la capacidad económica de la familia o allegados y del repertorio y moda de los materiales disponibles para este fin en las proximidades de las distintas necrópolis; sin descartar la influencia que pudieron ejercer las empresas fúnebres encargadas de organizar los sepelios, especialmente los basados en la cremación, que necesitaban de profesionales al efecto y que contarían con su propia gama de productos, tanto locales como foráneos, listos para ofrecer a sus clientes.

\section{HACIA UN ESTUDIO INTEGRAL DE LAS URNAS DE TRADICIÓN INDÍGENA EN ÁMBITO FUNE- RARIO}

Resulta, pues, indudable que las urnas de tradición indígena, tanto por la forma como por la decoración, son uno de los nexos de unión más claros entre las necrópolis de época prerromana (en caso de existir) y romana. Precisamente, su presencia en contextos altoimperiales ha sido objeto de un intenso debate entre los que defienden un lógico incremento de este tipo de contendores procedentes del comercio local, más económico, frente a las producciones importadas por los itálicos, y los que apuestan por ver en ellas un signo indudable de etnicidad, especialmente, en la esfera de lo funerario. 
Como señalábamos al inicio de este trabajo, la falta de información sobre las actividades funerarias de la Corduba prerromana y republicana hace prácticamente imposible plantear si el uso de las urnas de tradición indígena en la capital de la Bética responde a un gesto de continuidad con respecto a los rituales oriundos de la zona o es el resultado de un proceso de fusión e hibridismo entre las costumbres de ambas comunidades (local y foránea). En este sentido, la única urna que podemos vincular a los primeros momentos de ocupación romana en la ciudad, datada a principios del s. II a.C. (Murillo y Jiménez 2002: 186), presenta bastante similitudes con el Tipo II planteado por B. García Matamala (2002-2003), lo que demostraría, según J. L. Jiménez Díez (2008: 345), que este tipo de recipientes debían ser asimilados por los habitantes de la región con formas tradicionales presentes durante generaciones en el territorio; algo similar a lo planteado para Tarraco (Remolà 2004), Valentia (García Prósper y Guérin 2002), Carthago Nova (Ramallo 1989) o Lucentum (Jiménez Salvador y Ribera 2002).

Así pues, las urnas de tradición indígena podrían estar perpetuando, en uno de los elementos más importantes del ajuar funerario, la herencia de un mundo anterior, ensalzado y potenciado como medida de choque ante los nuevos habitantes y sus costumbres de enterramiento ( $\mathrm{Ji}$ ménez Díez 2006; 2008: 344). A ello apuntaría el hecho de que estas ollae ossuariae aparezcan asociadas a las primeras importaciones itálicas, así como a las imitaciones de este tipo de vajilla y, aún más, a las primeras hornadas de terra sigillata hispánica procedentes del alfar de Andújar. Sin embargo, el empleo de urnas de tradición indígena junto a ajuares de origen local (caso de Castulo, Carmo, Baelo Claudia y Onoba, entre otras), con una ausencia total de terra sigillata, ha sido utilizado como argumento para el afianzamiento étnico de la cultura precedente frente a la invasora (Bendala 1976; Bustamante 2010; Fernández Sutilo 2016); un debate todavía abierto y en vías de enriquecimiento con posturas tan contradictorias como la defendida por J. L. Escacena y M. Belén (1994: 237-265), para quien la cultura turdetana no habría dejado huella arqueológica dada su relación con las tradiciones funerarias atlánticas ${ }^{2}$.

No obstante, como ya hemos comentado anteriormente contamos con opiniones que ven en las urnas de tradición indígena el carácter humilde de los difuntos que albergan, sin solvencia para costearse un contenedor funerario de mayor valor económico, recurriendo al uso de este tipo de cerámica común, accesible a todos los sectores de la sociedad. De hecho, los enterramientos de tradición indígena identificados en Córdoba corresponden en todos los casos a estructuras sencillas, lo que descarta a priori su utilización por parte de las élites sociales. La única excepción la

\begin{tabular}{|c|c|c|c|c|}
\hline Enterramiento & Sexo & Tipología & Ajuar primario & Ajuar secundario \\
\hline Enterramiento 23 & ¿? & Tipo III & - & Ungüentario vidrio y varilla metálica \\
\hline Enterramiento 24 & $¿ ?$ & Tipo V & - & - \\
\hline Enterramiento 25 & ¿? & Tipo V & Oso & - \\
\hline Enterramiento 27-A & M & Tipo III & - & - \\
\hline Enterramiento 27-B & M & Tipo V & - & Ungüentario vidrio \\
\hline Enterramiento 28 & $¿ ?$ & Tipo V & - & Ungüentario vidrio \\
\hline Enterramiento 29 & ¿? & Tipo III & Ciervo y ave pequeña & Ungüentario vidrio \\
\hline Enterramiento 44 & ¿? & Urna de vidrio & - & Ungüentario vidrio \\
\hline Enterramiento 45 & $¿ ?$ & Tipo IV-A & - & Ungüentario vidrio \\
\hline Enterramiento 46-A & M & Tipo II & Ungüentario vidrio & - \\
\hline Enterramiento $46-\mathrm{B}$ & $\mathrm{M}-\mathrm{V}$ & Tipo III & - & Cajita metálica \\
\hline Enterramiento 56 & M & Tipo II & - & Ungüentario vidrio \\
\hline Enterramiento 57 & ¿? & Tipo V & - & - \\
\hline Enterramiento 58 & $¿^{?} ?$ & Tipo II & Ungüentario vidrio & - \\
\hline
\end{tabular}

Fig. 8: Tabla de enterramientos del Recinto Funerario G de la necrópolis de Llanos del Pretorio en Córdoba. Elaboración propia. 
encontramos en la urna aparecida en el monumento funerario de tipo semihipogeico de la Calle La Bodega, que se hizo acompañar además de un rico ajuar, lo que hace suponer su pertenencia a un miembro de alta categoría social (García Matamala 2002-2003: 265).

Hasta hace poco el análisis de estos contenedores cerámicos no permitía abordar la problemática específica en cuanto a la interpretación de etnia, género, edad o estatus social, tanto por la descontextualización de los hallazgos y estado de conservación, como por la falta de estudios pormenorizados. En este sentido, el hallazgo del sepulcretum de Llanos del Pretorio, el sector funerario que hasta el momento ha aportado una mayor cantidad de este tipo de urnas, supone un antes y un después en el conocimiento de los usos y costumbres relacionadas con ellas, puesto que han sido sometidas a un proceso de microexcavación en laboratorio, contando a continuación con un exhaustivo estudio antropológico (García-Prósper y Polo 2020: 161-172).

Las primeras conclusiones apuntan a un uso indistinto de las distintas tipologías de urnas por parte de hombres y mujeres. Tan sólo las urnas del Tipo IV-A han ofrecido restos vinculados a varones de forma exclusiva; si bien, la muestra es tan minoritaria que resulta complicado confirmar esta relación en términos absolutos. Algo similar a lo que ocurre si analizamos los casos según el rango de edad: aunque existe una predilección por las urnas de tradición indígena del Tipo $\mathrm{V}$ en el caso de las inhumaciones infantiles, seguramente por razones prácticas debido a sus grandes dimensiones, lo cierto es que han aparecido también en el interior de ánforas y entre dos tegulae. Por su parte, las cremaciones infantiles se han localizado en urnas de los Tipos III y IV-B, destacando un individuo a pretérmino introducido en una urna del Tipo IV-A, dando cuenta de las distintas casuísticas.

Si consideramos la distribución de los recipientes de tradición indígena en los diferentes recintos funerarios descubiertos en Llanos del Pretorio, aparecen en siete de las 15 estructuras identificadas. El Recinto Funerario G es el que acumula un mayor número de enterramientos de este tipo, con un total de 13 (fig. 8). Por el contrario, los Recintos Funerarios C, E, F, O y P contaban con una urna de tradición indígena en cada caso, bien acompañada de otros enterramientos, bien como protagonista absoluta del recinto. Este es el caso del Recinto Funerario C, que contaba con una única cremación en urna de tradición indígena (Tumba 30), sin ningún tipo de ajuar. Por lo que se refiere al Recinto Funerario F, sin duda, el más “monumental" de los excavados, con muros de mampostería en sus cuatro lados y una entrada escalonada en piedra, se han localizado un total de tres cremaciones, de las cuales dos fueron localizadas en el interior de dos urnas de piedra (Enterramiento 43 y 59) con sendos ungüentarios de vidrio, y otra más en urna de tradición indígena (Enterramiento 48), sin ningún tipo de ajuar. Los datos con los que contamos para los Recintos Funerarios $\mathrm{O}$ y $\mathrm{P}$ son muy escasos, dado que quedaban fuera de los límites de la intervención, estando además muy dañados por el muro pantalla del bloque de viviendas en construcción. Aun así, ha sido posible plantear su vinculación con varios enterramientos de cremación en urna de tradición indígena, que conservaban, además, un rico ajuar.

Atendiendo a la cronología de todo este conjunto, que en ningún caso podemos asociar a un sector socio-económico elevado, la vida útil del mismo no excedería los 6070 años, funcionando como necrópolis desde finales de época augustea hasta un momento impreciso de finales de época neroniana y flavia (Vargas y Hernández 2020: 105110). Por lo que a las urnas de tradición indígena se refiere este abanico cronológico resulta realmente interesante puesto que nos estamos moviendo en un momento plenamente altoimperial, en el que destaca la ausencia de armamento, característico de las tumbas de época prerromana, y la presencia de cerámicas de importación (barniz negro o campaniense, terra sigillata itálica, paredes finas, lucernas y ungüentarios) como parte del ajuar, lo que demuestra, sin ningún género de dudas, la conformación de un ritual de carácter híbrido, en el que los elementos de ambas culturas se van integrando, adaptando y asimilando como consecuencia de un contacto continuo y directo que se inició con la llegada de los contingentes militares a partir del s. III a.C. para eclosionar en época julio-claudia, conformando un paisaje funerario típicamente romano, caracterizado por viae sepulcrales flanqueadas por recintos lotificados y grandes monumentos funerarios que se combinan con amplios sectores de cremación e inhumación.

Llegados a este punto, la última pregunta que cabría plantear es si los finados en la necrópolis de Llanos del Pretorio eran individuos de raigambre indígena o personas procedentes de otras regiones del Imperio, sin descartar la posibilidad de encontrarnos ante ambientes heterogéneos con representantes de ambos grupos. Esta aclaración permitiría dar respuesta definitiva a si el uso de las urnas de tradición indígena era una mera moda del momento o si se trataba de un elemento diferenciador de un grupo concreto. Por desgracia, seguimos sin contar con una respuesta definitiva, ya que la realidad arqueológica no nos permite ir 


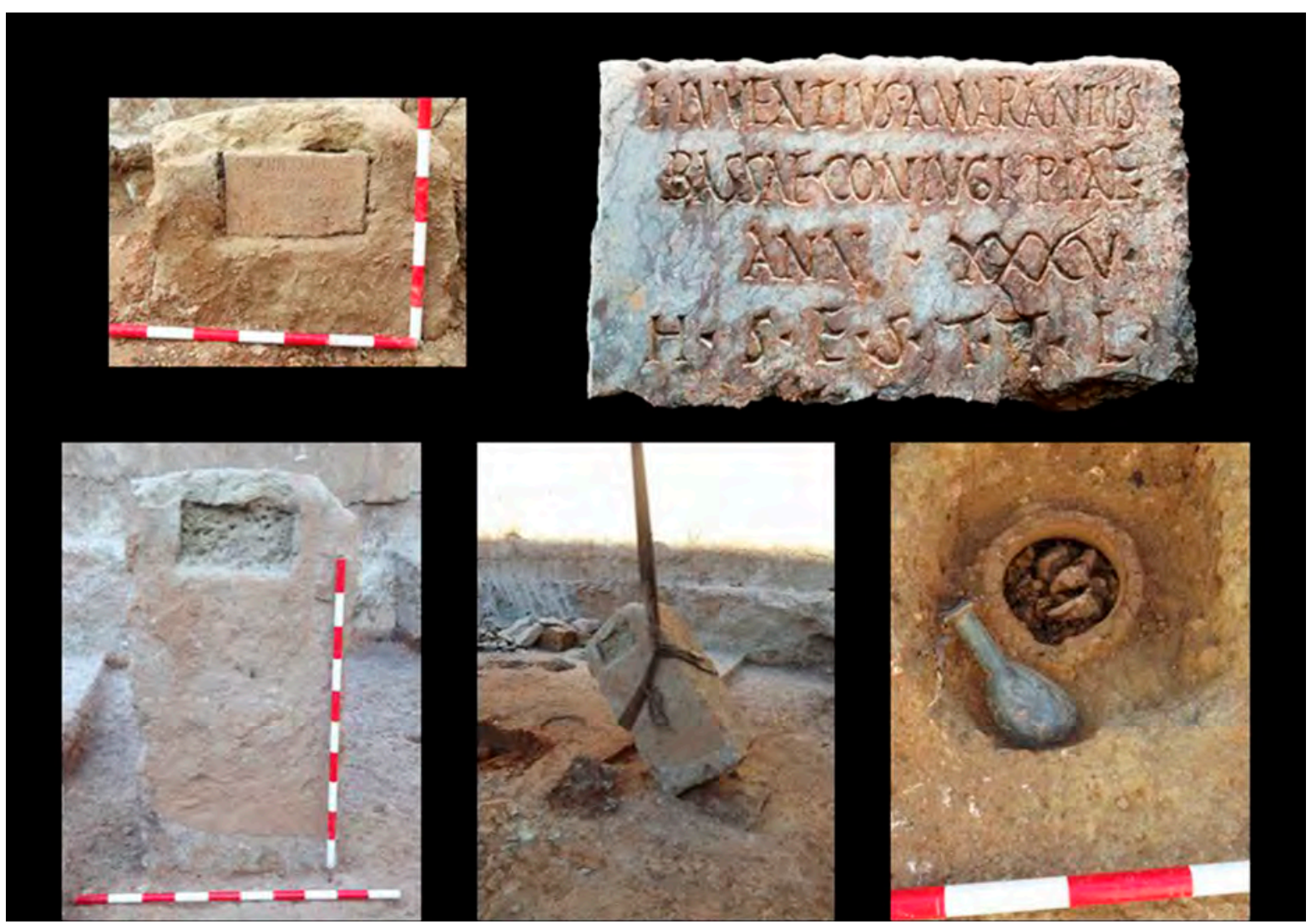

Fig. 9: Enterramiento en urna de tradición indígena con cipo señalizador y epitafio perteneciente a Bassa (Tumba 60 de la necrópolis de Llanos del Pretorio en Córdoba). Elaboración propia.

más allá de ciertas conjeturas, necesitando de estudios genéticos que, de momento, no se han podido realizar, sobre todo, si tenemos en cuenta la propia naturaleza del material óseo recuperado: cremaciones completas que alcanzaron altas temperaturas y afectaron a la calidad de las muestras.

Dentro de este panorama desolador, destaca la Tumba 60, una de las últimas realizadas en la necrópolis de Llanos del Pretorio (fig. 9). Se trata de un enterramiento en fosa simple con cubierta de tégula plana que acogía en su interior una urna de tradición indígena del Tipo III, acompañada de un ungüentario de vidrio, que ha permitido fecharla entre época tiberiana y neroniana (Rubio 2020: 87-88). Sobre la tumba se dispuso un cipo funerario de gran tamaño con tabla epigráfica incrustada en la que se hace referencia a la difunta, de nombre Bassa, y al dedicante, su esposo: I. Iuuentus Amarantus. Nos encontramos ante un contubernio entre un liberto y una esclava que, en principio, muestran una onomástica de origen latino. Bassus/a, y todas sus variantes, fue un nomen y cognomen de gran difusión en época romana, que haría referencia a una característica particular relacionada con el físico: la altura; si bien, hay epigrafistas que plantean un origen no latino (Kajanto 1982: 244), tal vez etrusco o griego, pero en ningún caso propio de los pueblos prerromanos hispanos. De igual modo, la inscripción funeraria localizada in situ en el bustum-ustrinum excavado en el solar de la sede de EMACSA muestra los nombres completos de dos personajes de origen servil (Cánovas et al. 2006: 291-293): Cornelia Nymphe, liberta de Quinto, y Caius Pomponius Statius, posible liberto que ha eliminado la referencia a la filiación. De nuevo, nos encontramos ante las típicas fórmulas latinas en el uso de la onomástica, así como la procedencia griega del cognomen femenino, siguiendo los parámetros propios de la época, lo que de momento hace imposible plantear un binomio claro entre las urnas de tradición indígena y su uso por parte de un sector de la sociedad cordubense de raigambre local. 


\section{NOTAS}

1. Pese a la ausencia de cerámica fina de mesa, la presencia de lucernas Dressel 3 y 11, cerámica tipo Peñaflor y un ungüentario Isings $28 \mathrm{~b}$ apuntan hacia esta cronología.

2. En este sentido, cabe destacar los últimos descubrimientos del yacimiento de La Silla del Papa (Moret et al. 2017: 49-71), junto a la ciudad romana de Baelo Claudia, con una necrópolis de cremación vinculada al poblado prerromano y época republicana, que podría cambiar lo hasta ahora establecido.

\section{AGRADECIMIENTOS}

Agradecemos a todos los arqueólogos que nos han cedido la información de sus excavaciones y a los integrantes de la Oficina de Arqueología de la Gerencia Municipal de Urbanismo del Ayuntamiento de Córdoba por facilitarnos la consulta de algunos expedientes. También a José María Tamajón, por la elaboración de la Figura 5 y del material gráfico procedente de Llanos del Pretorio.

\section{BIBLIOGRAFÍA}

ABASCAL, J. M. (1986): La cerámica pintada romana de tradición indígena en la Península Ibérica: centros de producción, comercio y tipología, Madrid.

BENDALA, M. (1976): La necrópolis romana de Carmona (Sevilla), Sevilla.

BLANCO, A. (1959): Excavaciones arqueológicas en la provincia de Jaén, Boletín del Instituto de Estudios Giennenses VI 22, 89-125.

BLANCO, A. (1960): Orientalia II, AEspA XXXIII, 3-43. DOI: https://doi.org/10.2307/334487

BUSTAMANTE, M. (2010): El comercio de Terra Sigillata altoimperial en el Círculo del Estrecho. Balance historiográfico y líneas de investigación, B.A.R.-I.S. 2148, Oxford.

BUSTAMANTE, M. (2016): La cerámica pintada romana de tradición indígena en el territorio de Extremadura, SPAL, 25, Sevilla, 183-207.

CABRÉ, J. (1925): Arquitectura hispánica. El sepulcro de Toya, Archivo Español de Arte y Arqueología 1, Madrid.

CAMPOS, J. M. (1989): Análisis de la evolución espacial y urbana de Urso, Estudios sobre Urso. Colonia Iulia Genetiva (J. González, ed.), Sevilla, 281-302.

CANO, J. I. (2003): Informe Preliminar de la Intervención Arqueológica de Urgencia Parcela 2 de la UA SR-9, Córdoba (C) Pintor Racionero Castro), Informe inédito.

CÁNOVAS, A.; SÁNCHEZ, S.; VARGAS, S. (2006): La tumba de Caius Pomponius Statius en la necrópolis septentrional de Colonia Patricia, $A A C$ 17.I, 279-296.
CHAPA, T.; PEREIRA, J.; MADRIGAL, A.; MAYORAL, V. (1998): La necrópolis ibérica de los Castellones de Ceal (Hinojares, Jaén), Sevilla.

CHAVES, T. (ed.) (2002): Urso. A la búsqueda de su pasado, Osuna. CONDE, M. J. (1998): Estado actual de la investigación sobre la cerámica ibérica pintada de época plena y tardía, REIb, 3 , 299-335.

CUADRADO, E. (1981): Las necrópolis peninsulares en la Baja Época de la Cultura Ibérica, La Baja Época de la Cultura Ibérica, Madrid, 51-69.

ESCACENA, J. L. (1987): Cerámicas a torno pintadas andaluzas de la Segunda Edad del Hierro, Tesis Doctoral, Universidad de Cádiz.

ESCACENA, J. L.; BELÉN, M. (1994): Sobre las necrópolis turdetanas, Homenaje al Profesor Presedo (P. Sáez, S. Ordóñez, eds.), Sevilla, 237-265.

FERNÁNDEZ SUTILO, L. (2016): Espacios y usos funerarios en Onoba y su área de influencia entre los siglos II a.C.-VII d.C., Tesis Doctoral inédita.

GARCÍA GELABERT, M. P.; BLÁZQUEZ, J. M. (1992): Las necrópolis oretanas de Cástulo. Paralelos con las necrópolis ibéricas del sureste, Congreso de Arqueología ibérica. Las necrópolis (Madrid, 1991), Serie Varia, 455-472.

GARCÍA MATAMALA, B. (2002): Enterramientos de tradición indígena en Corduba, Espacios y usos funerarios en el Occidente Romano (D. Vaquerizo, ed.), Córdoba, 275-296.

GARCÍA MATAMALA, B. (2002-2003): Enterramientos de tradición indígena en Corduba, AAC 13-14, 251-278.

GARCÍA MATAMALA, B.; LIÉBANA, J. L. (2006): Inhumaciones infantiles de tradición indígena en un sector de la necrópolis oriental de Corduba, AAC 17.1, 99-114.

GARCÍA PRÓSPER, E.; GUÉRIN, P. (2002): Nuevas aportaciones en torno a la necrópolis romana de la Calle Quart de Valencia (s. II a. C.-IV d. C.), Espacios y usos funerarios en el Occidente Romano (D. Vaquerizo, ed.), Córdoba, 203-215.

GARCÍA PRÓSPER, E.; POLO, M. (2020): Estudio bioantropológico y paleopatológico del sepulcretum de Llanos del Pretorio, El sepulcretum de Llanos del Pretorio (Córdoba España) (D. Vaquerizo, A. Ruiz Osuna, M. Rubio, eds.), Edipuglia, 161-172.

GUTIÉRREZ SOLER, L. M.; IZQUIERDO, I. (2001): Análisis arqueológico e interpretación de los espacios funerarios del oppidum de Giribaile en el territorio del Valle del Guadalimar (Jaén), AEspA 74, 35-52.

DOI: https://doi.org/10.3989/aespa.2001.v74.146

JIMÉNEZ DÍEZ, A. (2006): Contextos funerarios en la transición del mundo prerromano al romano en el sur peninsular, Anarcor 17.1, 67-98.

JIMÉNEZ DÍEZ, A. (2008): Imagines Hibridae. Una aproximación postcolonialista al estudio de las necrópolis de la Bética, Anejos de Archivo Español de Arqueología 43, Madrid. 
JIMÉNEZ SALVADOR, J. L.; RIBERA, B. (coords.) (2002): Valencia y las primeras ciudades romanas de Hispania, València.

KAJANTO, I. (1982). The Latin cognomina, Giorgio Bretschneider. LÓPEZ JIMÉNEZ, A. (2006): Informe y Memoria. Parcela 4 del Plan Especial SC-2a, 06, Informe inédito.

LÓPEZ JIMÉNEZ, A. (2009): A.A.P. Plan Especial SC2A Parcelas 3 y 4 (Córdoba), Anuario Arqueológico de Andalucía 2004.2, 313-325.

LÓPEZ PALOMO, L. A. (2003): Intervención Arqueológica de Urgencia en calles Joaquín Sama Naharro y Pintor Palomino, Informe inédito.

LÓPEZ PALOMO, L. A. (2004): Actuación Arqueológica Preventiva en el solar de La calle Beatriz Enríquez, esq. con Avda. del Brillante, de Córdoba, Informe inédito.

MÁRQUEZ, C. (1998): La decoración arquitectónica de Colonia Patricia. Una aproximación a la arquitectura y urbanismo de la Córdoba romana, Córdoba.

MÁRQUEZ, C. (2002), La ornamentación arquitectónica en ámbito funerario de Colonia Patricia, Espacio y usos funerarios en el Occidente romano (D. Vaquerizo, ed.), vol. II, Córdoba, 223-247.

MARTÍN BLANCO, C. (2007): Informe y Memoria de la Intervención Arqueológica Preventiva en la Calle Antonio Maura $N^{o} 10$ de Córdoba, Informe inédito.

MERGELINA, C. (1944): Tugia. Reseña de unos trabajos, Boletín del Seminario de Estudios de Arte y Arqueología X, 13-32.

MORET, P.; PRADOS, F.; FABRE, J.-M.; FERNÁNDEZ, E.; GARCÍA, F. J.; GONZÁLEZ, F.; JIMÉNEZ-VIALAS, H. (2017): La Silla del Papa: hábitat y necrópolis, Mélanges de la Casa de Velázquez 47 (1), 49-71. DOI: https://doi.org/10.4000/mcv.7333

MURILLO, J. F.; JIMÉNEZ, J. L. (2002): Nuevas evidencias sobre la fundación de Corduba y su primera imagen urbana, Valentia y las primeras ciudades romanas de Hispania (J. L. Jiménez Salvador, A. Ribera, coords.), Valencia, 183-193.

NÚÑEZ, E.; MUÑOZ, J. (1990): Excavaciones en la Necrópolis del Cerro de las Balas, Écija, Anuario Arqueológico de Andalucía 1988, Tomo III, 429-433.

OLMOS, R.; ROUILLARD, P. (eds.) (2004): La vajilla ibérica en época helenística (siglos IV-III al cambio de Era), Actas del Seminario celebrado en la Casa de Velázquez, Madrid.

PEREIRA, J. (1988): La cerámica ibérica de la cuenca del Guadalquivir. I: Propuesta de clasificación, TP 45, 143-173. DOI: https://doi.org/10.3989/tp.1988.v45.i0.608

PEREIRA, J. (1989): La cerámica ibérica de la Cuenca del Guadalquivir II. Conclusiones, TP 46, 149-159. DOI: https://doi.org/10.3989/tp.1989.v46.i0.592

PEREIRA, J.; CHAPA, T.; MADRIGAL, A.; URIARTE, A.; MAYORAL, V. (eds.) (2004): La Necrópolis ibérica de Galera (Granada), Madrid.
PRADOS, F. (2016): La materialidad de la muerte en la necrópolis de Baelo Claudia. Ritos y creencias en contexto, AEA 89, 273-291. DOI: https://doi.org/10.3989/aespa.089.016.013

RAMALLO, S. F. (1989): Cartagena, la documentación arqueológica, Murcia.

REMOLÀ, J. A. (2004): Arquitectura funeraria, Las capitales provinciales de Hispania III, Tarragona, Colonia Iulia Vrbs Triumphalis Tarraco (X. Dupré, ed.), Roma, 83-95.

RUBIO, M. (2019): Informe-Memoria del Seguimiento Arqueológico en Avenida Llanos del Pretorio $N^{o} 1$ y 3 (Córdoba), Informe inédito.

RUBIO, M. (2020): Las prácticas funerarias en la necrópolis de Llanos del Pretorio, El sepulcretum de Llanos del Pretorio (Córdoba - España) (D. Vaquerizo, A. Ruiz Osuna, M. Rubio, eds.), Edipuglia, 79-89.

RUIZ, A.; MOLINOS, M. (1993): Los iberos: análisis arqueológico de un proceso histórico, Barcelona.

RUIZ OSUNA, A. (2007a): La monumentalización de los espacios funerarios en Colonia Patricia Corduba (ss. I a.C. - II d.C.), Córdoba.

RUIZ OSUNA, A. (2007b): La historiografía local como herramienta de reconstrucción del mundo funerario en Colonia Patricia Corduba, Spal 16, 25-40. DOI: https://doi.org/10.12795/spal.2007.i16.02

RUIZ OSUNA, A. (2010b): Viae sepulchrales y paisaje funerario, El anfiteatro romano de Córdoba y su entorno urbano. Análisis arqueológico (ss. I-XIII d.C.) (D. Vaquerizo, J. F. Murillo, eds.), Córdoba, 380-405.

RUIZ OSUNA, A. (2020): Las estructuras de cremación del sepulcretum de Llanos del Pretorio, El sepulcretum de Llanos del Pretorio (Córdoba - España) (D. Vaquerizo, A. Ruiz Osuna, M. Rubio, eds.), Edipuglia, 91-104.

SALINAS VILLEGAS, J. M. (2004): Intervención Arqueológica de Urgencia. Plan Especial Manzana Banesto SR-13, vol.I, II y III, Informe inédito.

VAQUERIZO, D. (1994): Muerte y escultura ibérica en la provincia de Córdoba. A modo de síntesis, REIb I, 247-289.

VAQUERIZO, D. (1999): La cultura ibérica en Córdoba. Un ensayo de síntesis, Córdoba.

VAQUERIZO, D. (2001a): Formas arquitectónicas funerarias de carácter monumental en Colonia Patricia Corduba, AEspA 74, 131-160.

DOI: https://doi.org/10.3989/aespa.2001.v74.151

VAQUERIZO, D. (2001b): Recintos y Acotados funerarios en Colonia Patricia Corduba, Madrider Mitteilungen 43, 169-205.

VAQUERIZO, D. (2020): Parcelaciones funerarias en necrópolis cordubenses. Reflexiones a partir de dos hallazgos recientes, AEspA 93, 147-172.

DOI: https://doi.org/10.3989/aespa.093.020.007

VAQUERIZO, D.; SÁNCHEZ, S. (2008): Entre lo público y lo privado. La indicatio pedaturae en la epigrafía funeraria hispana, AEspA 81, 101-131.

DOI: https://doi.org/10.3989/aespa.2008.v81.42 
VAQUERIZO, D.; RUIZ OSUNA, A.; RUBIO, M. (2019): Una nueva vía funeraria en Colonia Patricia (Córdoba): el sepulcretum de Llanos del Pretorio, Zephyrus 83, 79-105. DOI: https://doi.org/10.14201/zephyrus20198379105

VAQUERIZO, D.; RUIZ OSUNA, A.; RUBIO, M. (eds.) (2020): El sepulcretum de Llanos del Pretorio (Córdoba - España), Edipuglia.

VARGAS, S. (2002): El conjunto funerario de La Constancia (Córdoba). Ajuares y cronología, Espacios y usos funerarios en el Occidente Romano (D. Vaquerizo, ed.), Córdoba, 297-310.
VARGAS, S., HERNÁNDEZ, L. (2020): Los ajuares cerámicos en la necrópolis de Llanos del Pretorio, El sepulcretum de Llanos del Pretorio (Córdoba - España) (D. Vaquerizo, A. Ruiz Osuna, M. Rubio, eds.), Edipuglia, 105-110.

VARGAS, S., GUTIÉRREZ, M. I. 2004, Un ejemplo de los usos y costumbres funerarias de la Córdoba romana a través de un conjunto de tumbas de la necrópolis de la Avenida del Corregidor (Córdoba), AAC 15, 309-328.

VEGAS, M. (1973): Cerámica común romana del Mediterráneo occidental, Barcelona. 